\title{
Public access policy support programs at libraries

\author{
A roadmap for success
}

Editor's note: When NIH's Public Access Policy began to require that researchers deposit their publications in PubMed Central, authors, publishers, research officers, and librarians across the country rushed to clarify the details of the policy and to take a public stand on compliance. Having worked on such efforts in medical libraries and a research library, Molly Keener and Cathy Sarli here provide useful guidance on how to develop a program of support for researchers who are governed by the policy.

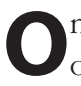
April 7, 2008, the National Institutes of Health (NIH) Public Access Policy became a requirement for all NIH-funded extramural researchers. Researchers are required to submit peer-reviewed manuscripts generated by NIH support upon acceptance of publication to PubMed Central with the full text to be available within 12 months of publication. Authors of applicable papers are also required to demonstrate compliance with the NIH Policy in NIH proposals, applications, and progress reports.

The enactment of the NIH Policy prompted the need for institutional awareness of compliance issues in a realm that traditionally has been left to the purview of authors: the publication and dissemination of research results. ${ }^{1}$

Recognizing gaps in knowledge and the potential for collaborative opportunities beyond the library, some libraries have implemented NIH Policy support programs. These programs involve partnerships with on- and off-campus groups, and may offer a wide range of services and resources such as education and training, personal consultations, Web sites, customized resources, third-party submission services, and related efforts in support of NIH-funded authors. NIH Policy support programs also create opportunities for libraries to introduce scholarly communication issues that can be difficult to address in a direct fashion, including author rights, open access, publishing models, and other peripheral issues. These tandem efforts foster contextual understanding and enhance awareness of issues that impact authors as well as libraries. What follows is an overview of program elements and keys for success to assist libraries seeking to support NIH-funded authors.

\section{Establishing a program: Needs assessment and levels of support}

Before a library launches a support program, staff should conduct a needs assessment to determine the extent of NIH funding at an institution and what services are warranted. Questions to be considered include:

- What percentage of external funding is supplied by NIH?

Molly Keener is scholarly communication librarian at Z. Smith Reynolds Library at Wake Forest University, e-mail: keenerm@wfu.edu, and Cathy Sarli is scholarly communications specialist at the Becker Medical Library at Washington University School of Medicine, e-mail: sarlic@wusm.wustl.edu

Contact Mike Furlough — series editor, assistant dean for scholarly communications, and codirector of the Office of Digital Scholarly Publishing at Penn State Universitywith article ideas, e-mail: mfurlough@psu.edu

C 2010 Molly Keener and Cathy Sarli 
- How many departments and authors receive NIH funding?

- Who works on NIH-funded research? Faculty? Post-doctoral fellows? Graduate students?

- How many articles are published annually from NIH-funded research?

- Are there other campus groups that provide support for NIH-funded authors?

Identifying the extent of NIH funding received by an institution by departments and authors, and the number of NIH-funded articles is not difficult, especially when working with a campus group such as an office that handles grant and contracts or sponsored research, or using databases such as PubMed, Web of Science, or NIH's RePORTER. ${ }^{2}$ One caveat to using PubMed and Web of Science is that retrieval of NIHfunded articles will only be ballpark figures, as queries, even with grant and affiliation limits, are not perfect. Nevertheless, publication estimates for your institution can be helpful for assessing the potential impact of the NIH Policy locally.

Another important step of the needs assessment process is to determine what support for NIH Policy compliance, if any, is offered by other campus groups, such as administrative offices that handle research affairs, legal matters, or grants and contracts or sponsored research.

It is highly recommended to contact one of these campus groups before implementing a library-based program, especially the office that handles grants and contracts or sponsored research, to ensure that there is no duplication among efforts. The NIH Policy involves issues related to copyright as well as responsible conduct of research matters and compliance with grant award requirements.

One of the major caveats to implementing a library-based program is that the role of the library is to not interpret the NIH Policy. Just as libraries do not dispense medical advice, the same holds true for interpreting a policy. This demonstrates the importance of establishing a relationship with a cam- pus group that handles issues that require interpretation.

If some areas of compliance support are not provided by other campus groups, the library should focus on addressing the gaps to create a coordinated campus-wide program of support that plays to the strengths of all groups involved. Any effort to create a library-based program should be one that is sustainable, even it is limited in scope in its initial development.

\section{Program elements: Resources, services and personnel}

Resources and services will evolve as a program develops, but a logical starting point is an institution-specific Web site on the NIH Policy. Flowcharts and handouts that outline the compliance process, providing point-of-need information in a straightforward, easily distributable format. Template letters to send to publishers and copyright addenda that allow authors to seek permission or retain the right to comply from publishers will save time for authors. If the institution has specific internal processes for researchers to follow with the NIH Policy, the Web site may include a FAQ for providing institution-specific answers to questions. Guidance documents, such as how to locate documentation of compliance or a listing of journal publisher policies, are also examples of resources helpful to authors.

Services for authors can vary, depending on the level of institutional need versus the ability of the library to provide sustainable services. Offer services that can be delivered confidently and completely. Specific services that might be offered through a library-based program include:

- providing guidance on compliance;

- reviewing publisher copyright forms;

- providing classes, workshops, and group presentations;

- researching publisher policies and contacting publishers for clarification;

- compiling field-specific journal lists;

- making "office calls" to assist with submission; 
- reviewing citations for proposals, applications, and progress reports;

- locating documentation of compliance;

- third-party submissions; and

- assisting with creating automated database alerts to monitor compliance.

Ultimately, libraries should be responsive in meeting the needs of authors. If authors request a specific resource or service, respond accordingly, if feasible.

Equally important is dissemination of updates about the NIH Policy and news related to program resources and services. Seek multiple outlets for sharing updates and news-avenues such as research office newsletters and electronic lists; blogs; new faculty and graduate student orientation; information packets in labs, offices, and lunchrooms; and presentations at faculty and departmental meetings are ideal ways to get the word out.

When planning a program, personnel issues are as important as the resources and services. If an individual will run the program, who is appropriate? The staffing model should be one that complements current responsibilities and workflow. If a team effort, the roles of the team should be clear to avoid duplication-why should every member of the team specialize in all facets of the NIH Policy? Any program should have at least one staff person willing to learn about the NIH Public Access Policy-the policy has many nuances and a simple inquiry can quickly evolve into a complicated question.

Be warned: the devil is in the details! Some questions involve complex issues that cannot be addressed without consultation with other groups. One example of an issue that required in-depth consultation with NIH, campus General Counsel, and the publisher involved clarification of a journal's status per NIH Policy. Knowledgeable individuals legitimize the program, and positive experiences are catalysts for change in the perception of the library.

Providing a library-based program is a dynamic process; building a Web site and dedicating staff to this effort is only the tip of the iceberg. Libraries should be proactive, continually assess the landscape during outreach efforts with authors and campus groups, keep abreast of author needs, monitor NIH releases and other resources for information on the NIH Policy, and tailor program resources and services, as needed.

Lastly, do not forget about researchers on nonmedical campuses. Either partner with a counterpart in the main campus library or open the program to all NIH-funded authors, regardless of campus affiliation.

\section{Keys to success: Partnerships and collaborations}

One of the key ingredients to successful implementation of a library-based program is to form partnerships with groups, both on- and off-campus. The ideal is a partnership with all on-campus units that provide support services for authors. Such partnerships are vital to expanding program outreach efforts and serve as a stamp of credibility for a library.

Relationships with off-campus units also serve a valuable purpose. One example is with NIH. Fielding questions from authors often requires contacting NIH for clarification. Establishing a relationship with a main contact person at NIH is highly recommended so that a library can report on feedback from authors on issues related to compliance that cause frustration, as well as learn of any new developments with the NIH Policy. NIH has a specific e-mail address devoted to NIH Policy questions, which are usually answered by the same person. ${ }^{3}$

Communicating with librarians from other research libraries who manage similar programs is helpful to share expertise and resource-sharing. Sample template letters, flowcharts, teaching materials, handouts, and other program resources can be shared by all libraries. Two resources that provide lists of research libraries and services/resources are Implementation Resources for the NIH Policy ${ }^{4}$ and SPEC Kit \#311: Public Access Mandates. ${ }^{5}$ And colleagues are helpful for venting, too. Not only can authors get frustrated by the compliance process but librarians, as well. 
Another example of off-campus partners are publishers of journals in which authors publish. This helps facilitate understanding of the various journal publisher polices for NIH-funded authors and to learn of any issues these authors may need to know.

While these collaborations help to leverage expertise and promote resource-sharing among all parties, cultivating these relationships takes time and effort.

\section{Keys to success: Be responsive and adaptive}

Another key to success is to be responsive and adaptive to the needs of authors. Program support will require varying levels of personnel involvement at certain points throughout the year, i.e., when progress reports are due. Be flexible in meeting times and locations-be willing to meet in authors' offices and outside of normal working hours.

Responding as soon as possible to requests for assistance is also recommended, as many authors wear multiple hats as investigators, faculty, mentors, and clinicians, and their schedules are often chaotic with multiple deadlines to meet. Answering e-mails over the weekend may help authors who are trying to complete a report or application. Flexibility in meeting the needs of authors is integral to program success.

Being responsive and adaptive also involves listening to what authors report. What part of the compliance process causes the most frustration? Is there a solution? Can the library create a product or offer a service that addresses a need? Solutions require time management on the part of libraries as well as meeting the expectations of users.

\section{Benefits}

There are a number of benefits to providing a program. Among the benefits are:

- partnerships with campus groups adds credibility to library efforts;

- provides a new perspective of the library;

- allows for identification of trends and issues that are impacting authors; and
- results in invitations from campus groups (academic and administration) to participate in projects not related to the NIH Policy;

- allows for subtle introduction of librarybased author support services/resources; and

- serves as a hook for serendipitous opportunities to introduce often misunderstood scholarly communication issues that would otherwise be difficult to do, especially author rights.

\section{Conclusion}

While public access policies are a relatively new development, the opportunities offered by providing a library-based program for compliance hold promise for libraries. Programs for NIH Public Access Policy compliance support provide a prime example of how libraries are evolving to address the complexity of research in the 21st century coupled with alliance building efforts beyond the library.

Efforts to leverage expertise and resource sharing for public access mandate support are evidence that libraries stand ready to efficiently respond to possible future policies, including the Federal Research Public Access Act (FRPAA). Such programs offer the potential of redefining the library as more than just books and dust.

\section{Notes}

1. Details of the policy and procedures for compliance can be found at publicaccess. nih.gov/.

2. PubMed, www.ncbi.nlm.nih.gov /pubmed/; Web of Science, www. isiwebofknowledge.com/; RePORTER, projectreporter.nih.gov/reporter.cfm

3. NIH responds to questions directed to PublicAccess@nih.gov.

4. Open Access Directory. Implementation Resources for the NIH Policy. Open Access Directory, oad.simmons.edu/oadwiki /Implementation_resources_for_the_NIH _policy.

5. Cathy C. Sarli, Ellen Dubinsky, Bob Engeszer, and Ruth Lewis, 2009, Spec Kit 311: Public Access Policies, Washington, D.C.: Association of Research Libraries. $\boldsymbol{n}$ 